\title{
Soot a major contributor to climate change
}

\section{Black carbon could result in twice as much global warming as previously estimated.}

\section{Jeff Tollefson}

15 January 2013

The contribution of soot to global warming is much higher than previously thought, according to a comprehensive assessment that ranks 'black carbon' second only to carbon dioxide in terms of its warming impact on the current climate.

Published online by the Journal of Geophysical Research, the four-year study roughly doubles most of the previous estimates of the warming that occurs when carbon particles absorb solar radiation, which heats the atmosphere and results in the melting of snow and ice. Black carbon's impact on the climate is larger than that of methane and roughly two-thirds that of carbon dioxide, according to the study 1 .

Although many scientists had suspected that global climate models underestimated the role of black carbon, the magnitude of the impact has surprised many of the

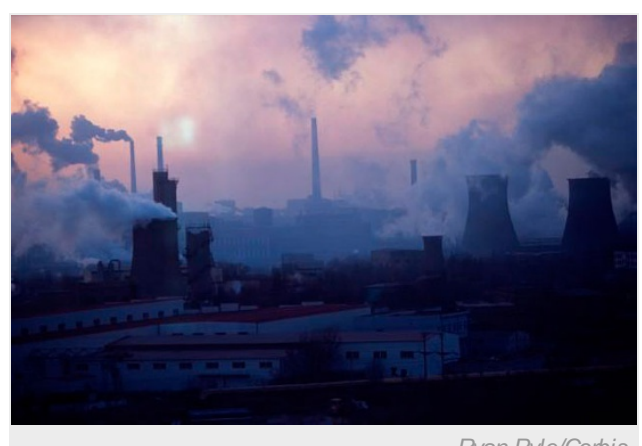

Ryan Pyle/Corbis

Soot is the second most important contributor to global warming, after carbon dioxide. report's authors, says David Fahey, an atmospheric scientist at the US National Oceanic and Atmospheric Administration in Boulder, Colorado, and a lead author.

Diesel emissions and agricultural waste fires are major sources of black carbon in industrialized countries, whereas in the developing world, the soot comes from sources such as burning of biomass for cooking and heat. "This study suggests we should be putting even more effort into reducing black carbon pollution," says Durwood Zaelke, who heads the Institute for Governance and Sustainable Development in Washington DC. Although $\mathrm{CO}_{2}$ dominates the long-term effect, understanding the timescale is crucial, Zaelke says. "Reducing black carbon gives you immediate cooling."

\section{Cutting carbon}

A study published in Science last year estimated that aggressive action on black carbon and methane could cut the rate of warming in half within the next 40 years $^{2}$. This is an appealing idea given the lack of progress for the United Nations climate negotiations, which often get hung up on carbon dioxide reductions. The Climate and Clean Air Coalition to Reduce Short-Lived Climate Pollutants, formed last year, now has 25 member countries, and is targeting reductions in diesel emissions and biomass cookstoves.

The latest report includes data from a ground-based aerosol sensor network, run by NASA, as well as satellite observations and global emissions inventories. The team used detailed atmospheric models to analyse the movement and evolution of aerosol particles. The results align well with the work of Veerabhadran Ramanathan, a climate scientist at the Scripps Institution of Oceanography in La Jolla, California, who has long emphasized black carbon's impacts on climate, regional weather and human health. Ramanathan says that the study seems to confirm the bigger impact that black carbon has on the temperature of the atmosphere, but does not answer questions about the overall effect of aerosols, which include climate-cooling particles such as sulphates. On this point, Ramanathan says, "there are no new insights from this study".

Fahey also acknowledges other uncertainties in the study. Although black carbon contributes to warming, the impact of aerosol emissions on climate could end up being significantly positive or negative. "It's not over yet, he says."

Nature I doi:10.1038/nature.2013.12225

\section{References}

1. Bond, T. C. et al. J. Geophys. Res. http://dx.doi.org/10.1002/grd.50171 (2012).

2. Shindell, D. et al. Science 335, 183-189 (2012). 